\title{
Displacement Ductility of Helically Confined HSC Beams
}

\author{
Muhammad N. S. Hadi* and Nuri M. Elbasha
}

School of Civil, Mining and Environmental Engineering, University of Wollongong, Wollongong 2522, Australia

\begin{abstract}
This paper presents an experimental investigation of the effect of helix pitch and helix diameter on beam behaviour through testing 10 helically confined beams. Two groups of beams had exactly the same geometry and reinforcement; with the only differences being the helices diameter and pitch. $8 \mathrm{~mm}$ helix was used in the first group of beams and $12 \mathrm{~mm}$ bars in the second group. The helix pitches varied between $25 \mathrm{~mm}$ and $160 \mathrm{~mm}$. Beams' cross section was $200 \times$ $300 \mathrm{~mm}$, with a length of $4 \mathrm{~m}$ subjected to four point loading. The main results indicate that the helical effectiveness is neglected when the helical pitch is $160 \mathrm{~mm}$ (helix diameter) and the displacement ductility index increases as the helical pitch decreases. Finally, there is a considerable release of strain energy responsible for spalling off the cover.
\end{abstract}

Keywords: Ductility, high strength concrete, reinforced concrete, helical reinforcement.

\section{INTRODUCTION}

The development of the construction industry has led to the continual improvement of construction materials, where high strength concrete of $100 \mathrm{MPa}$ compressive strength and reinforcement of $500 \mathrm{MPa}$ yield strength are being used in beams and other construction elements. High strength concrete (HSC) is used when the reduction in member cross section is required. The disadvantage of using HSC in over reinforced beams is its brittle failure. One option for changing the type of failure from brittle to ductile is through confining the compression region of the concrete. Helical reinforcement can be used to achieve the required ductility. It is generally accepted that helical confinement is more effective than the rectangular ties in increasing the strength and ductility of confined concrete. Helical reinforcement is effective for concrete under compression to increase the ductility as well as the compressive strength by resisting the lateral expansion due to Poisson's effect upon loading. Herein the helical reinforcement is used in the compression zone of the beams. The effectiveness of the helical confinement depends on variables such as helical pitch. This paper presents the experimental results of testing ten beams with $4000 \mathrm{~mm}$ length and a cross section of $200 \mathrm{~mm}$ in width and $300 \mathrm{~mm}$ in depth.

\section{COMPARISON BETWEEN HELIX AND TIE CON- FINEMENT}

Helical reinforcement can be used to achieve the required ductility. It is generally accepted that helical confinement is more effective than the rectangular ties in increasing the strength and ductility of confined concrete. Hatanaka and Tanigawa [1] stated that the lateral pressure produced by a rectangular tie is about 30 to 50 percent of the pressure introduced by a helix. That was in agreement with the experimental research conducted by Chan [2] who found that the

\footnotetext{
*Address correspondence to this author at the School of Civil, Mining and Environmental Engineering, University of Wollongong, Wollongong 2522, Australia; Tel: +61 24221 4762; Fax: +61 24221 3238;

E-mail:mhadi@uow.edu.au
}

efficiency of tie confinement is $50 \%$ of the helical confinement for the same lateral reinforcement ratio. The same effectiveness of confinement is applicable in columns and beams. Helix confines the concrete more effectively than rectangular ties as the helix applies a uniform radial stress on the concrete along the concrete member, whereas a rectangular tie tends to confine the concrete mainly at the corners. Thus the effective concrete area at the cross section is reduced because the concrete pressure will tend to bend the tie sides outward due to their low stiffness compared to the four corners [3]. As such a significant portion of the concrete in the cross section is considered as unconfined. On the other hand the arching of the concrete between the ties reduces the effective confined concrete at the cross section of the member. Thus using helical confinement in the compression zone of rectangular beams is more effective than using rectangular ties. Nevertheless, to prove experimentally that the helix is more effective than the rectangular ties, there is a need to compare beams helically confined with beams confined using rectangular ties. A study by Whitehead and Ibell [4] proved that the use of helical confinement is more effective than rectangular ties in beams.

\section{THE EFFICIENCY OF HELICAL CONFINEMENT}

Brittle failure (compression failure) could be prevented when the beam is designed as an under reinforced section as recommended by the codes of practice. However, providing longitudinal reinforcement ratio greater than the maximum recommended longitudinal reinforcement ratio increases the flexural capacity of the beam and at the same time will lead to brittle failure (non ductile failure). As such using reinforcement higher than the maximum is not recommended by the codes provision as ductility is an important factor related to human safety. Kwan et al. [5] found that the use of a higher steel yield strength as longitudinal reinforcement enhances the flexural strength of the beam section, but the flexural ductility is reduced. On the other hand the use of a higher steel yield strength as compression reinforcement might not have much beneficial effect on the flexural strength of the beam section, but the flexural ductility is 
enhanced. However, the most important issue is enhancing the concrete strength as well as its ductility.

There are different ways of improving the ductility of concrete in compression such as providing longitudinal compression reinforcement, by using randomly oriented steel fibres, or by installing helical or tie confinement in the compression zone. Comparison between those different methods to find the most effective method to enhance the strength and ductility of beams is presented below. Shah and Rangan [6] tested 24 groups of beams for comparison of ductility. The test was designed to be under four point loading to ensure failure in the central constant moment zone. This central zone contained closed stirrups of varying volumes, steel fibres of different amounts or compression longitudinal reinforcement of different volumes. The test results showed that the ductility of beam confined using tie confinement was 10 times the ductility of the control beams (without any ductility reinforcement), while the fibres increased ductility 4.5 times and compression steel increased ductility twice the control beams. This result shows that the tie confinement is more effective than the compression longitudinal reinforcement and steel fibre for enhancing the ductility. Also the beams, which have longitudinal compression reinforcement, suffer from early failure because of the compression reinforcing buckling problem. Furthermore Mansur et al. [7] and Ziara et al. [8] found that the mid-span displacement ductility of beams enhanced significantly by using rectangular tie confinement. As a result of the experimental program conducted by Shah and Rangan [6], which proved that providing confinement in the compression zone of the beam is more efficient than providing steel fibres or compression longitudinal reinforcement. Also most of the literature, such as Park and Paulay [3], Sheikh and Uzumeri [9], Hatanaka and Tanigawa [1] and Cusson and Paultre [10] prove that the helical confinement is more effective than rectangular tie confinement. In addition the efficiency of helical confinement was recognized by several building codes such as [11, 12]. However since 1971, ACI-318 [12] use an equation for calculating the rectangular confinement required which is derived based on the efficiency of rectangular confinement is $50 \%$ of the helical confinement.

\section{EXPERIMENTAL PROGRAM}

The main concept of this study is to encase the concrete in the compression zone by installing helical confinement in the compression zone. The helix will confine the concrete, and as well as improving its strength, it will enhance its ductility and prevent brittle failure.

A previous model test program was carried by Hadi and Schmidt [13], wherein a total of seven beams were cast and tested. The results of testing these beams were encouraging; these form the basis of this study to focus on the effect of helical pitch on over reinforced helically confined HSC beams. The experimental program presented in this paper is part of an on going research to study the behaviour of over reinforced helically confined HSC beams. See for example Elbasha and Hadi [14].

Sheikh and Uzumeri [9] examined the effect of different variables on the strength and ductility of columns by testing 24 specimens. The results pointed to the significant influence of the helical pitch on the behaviour of confined concrete. Shin et al. [15] tested 36 beams, four of which were to study the effect of tie spacing on ductility. The results did not clearly show the importance of confinement spacing. It may be because the spacings studied were only $75 \mathrm{~mm}$ and 150 $\mathrm{mm}$, which did not provide adequate data to determine the importance of confinement spacing. Hadi and Schmidt [13] tested six beams helically confined in the compression zone and the seventh beam as unconfined beam (with no helix). The six beams had the same helical pitch of $25 \mathrm{~mm}$ to study the influence of different variables excluding the helical pitch. However, the literature indicate the importance of helical pitch, but there is no quantitative data for over reinforced helically confined HSC beams.

The aim of the experimental program in this study is to investigate the behaviour of over-reinforced HSC helically confined beams and determine the effect of helix pitch on ductility. In the test program reported herein, a total of ten beams were cast in two batches, each batch had five different helical pitches, namely 25, 50, 75, 100 and $160 \mathrm{~mm}$. The helical pitch $160 \mathrm{~mm}$ chosen to verify if the effect of confinement is negligible when the helical pitch is equal to the confinement core diameter. This is based on the experimental results conducted by Iyengar et al. [16] and Martinez et al. [17]. Iyengar et al. [16] and Martinez et al. [17] found that the helical confinement has negligible effect when the helical pitch is equal to the diameter of confined concrete core. Based on these findings, this study did not include testing a control beam with no helical confinement. In addition, Hadi and Schmidt [13] include the testing of unconfined control beam (with no helix) as a basis for comparison with helically confined concrete beams. The behaviour of the control beam was shown to be very brittle in its failure, providing no plateau region in its load-deflection curve.

All ten beams had the same dimensions; generic details of the beams are shown in Fig. (1). Each beam was rein-
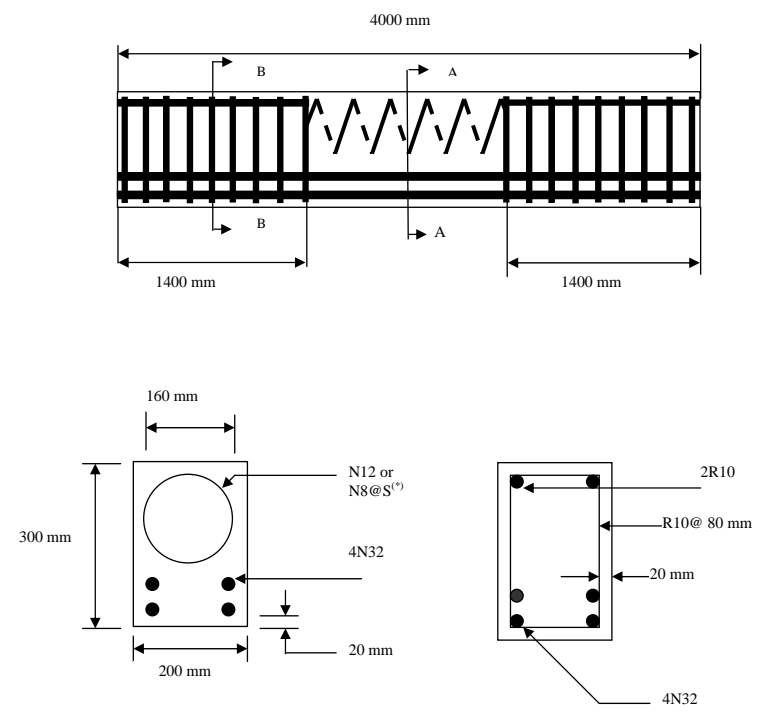

$\mathrm{S}^{(*)}=25,50,75,100$ and $160 \mathrm{~mm}$

SECTION A- A

SECTION B-B

Fig. (1). loading configuration and specimen details. 
forced with $4 \mathrm{~N} 32$ bars (32 mm deformed bars of $500 \mathrm{MPa}$ tensile strength and of normal ductility). Stirrups of plain 10 $\mathrm{mm}$ diameter (250 $\mathrm{MPa}$ tensile strength) were provided at either third end of the beams at a spacing of $80 \mathrm{~mm}$. Two 10 $\mathrm{mm}$ plain bars were installed at the top of the beams at either third in order to keep the ties in-place. For the first five beams the helix was made of $12 \mathrm{~mm}$ plain bars and for the second five beams the helix was made of $8 \mathrm{~mm}$ plain bars. Each group of five beams were cast at the same day using five wooden moulds. The beams were then cured by covering them with wet Hessian bags.

The alphanumeric characters in the titles of the beams (e.g. 12HP25) have the following meaning: the first number presents the diameter of the helical steel. The two letters after the first number indicate that the only variable is the helical pitch. The second number refers to the helical pitch in $\mathrm{mm}$.

\subsection{Materials}

The helical reinforcement was made of $8 \mathrm{~mm}$ and $12 \mathrm{~mm}$ diameter plain bars with $500 \mathrm{MPa}$ yield strength. Each beam had four longitudinal deformed steel bars of $32 \mathrm{~mm}$ diameter and $500 \mathrm{MPa}$ tensile strength. Figs. $(\mathbf{2}, \mathbf{3})$ and (4) show the stress-strain curves of the tensile strength tests of the $8 \mathrm{~mm}$ and $12 \mathrm{~mm}$ helix and the longitudinal reinforcing bars. The concrete used in this experimental program was supplied by a local ready mix supplier. The concrete compressive strength of the first five beams was $105 \mathrm{MPa}$ at the time of

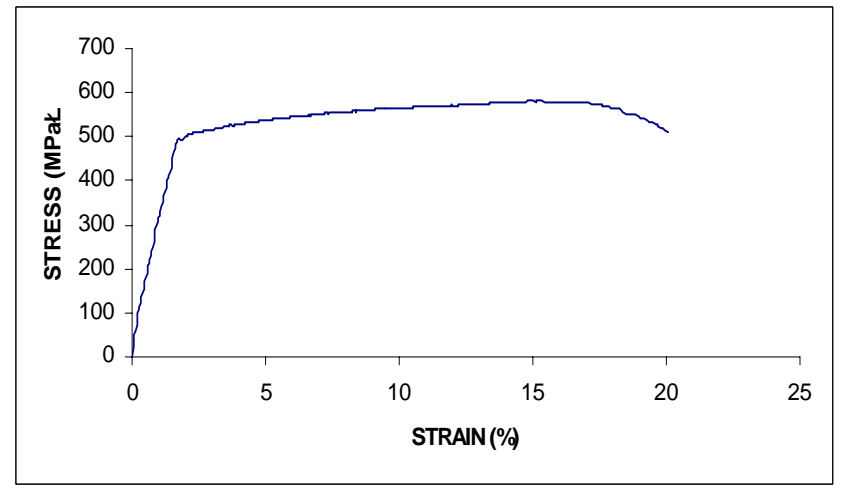

Fig. (2). Tensile stress strain curve for helical steel with $8 \mathrm{~mm}$ diameter.

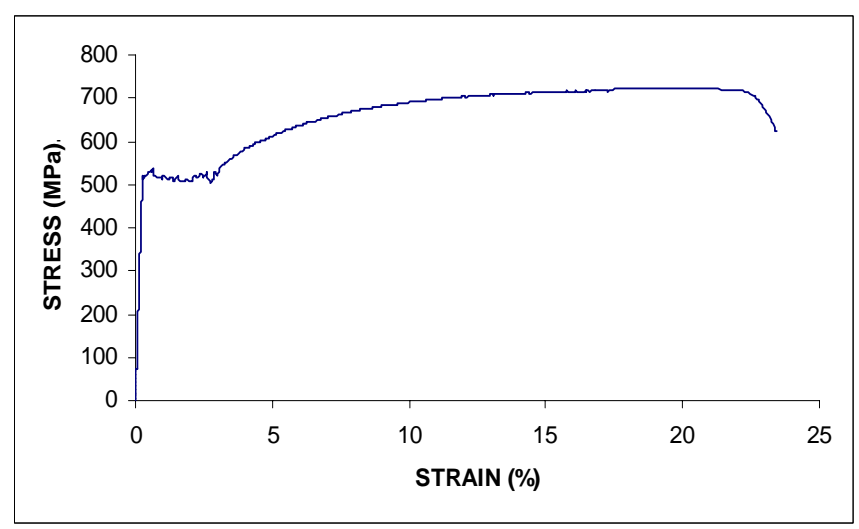

Fig. (3). Tensile stress strain curve for helical steel with $12 \mathrm{~mm}$ diameter.

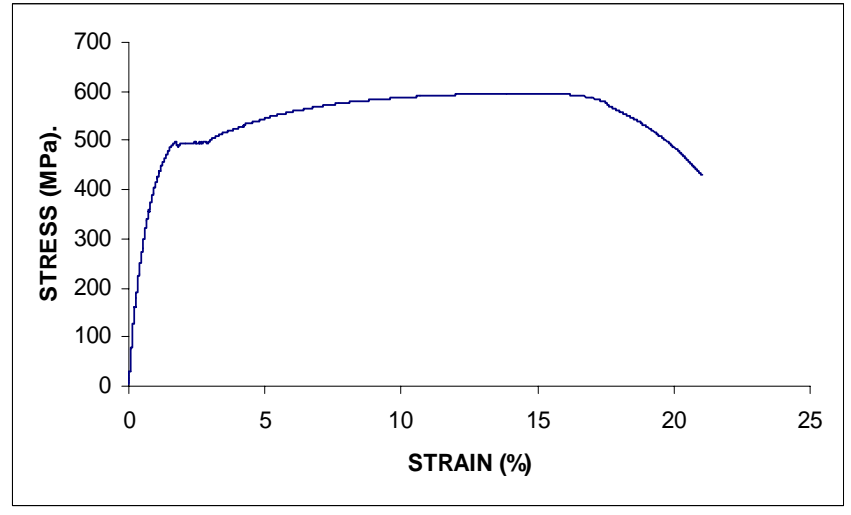

Fig. (4). Tensile stress- strain curve for longitudinal steel with 32 mm diameter.

testing, and the concrete compressive strength of the second five beams was $80 \mathrm{MPa}$ at the time of testing.

\subsection{Instrumentation}

All beams were heavily instrumented. The deformation in the reinforcement bars was measured using electrical resistance strain gauges (10 $\mathrm{mm}$ length) glued to the steel bars at mid-span of the beam and $300 \mathrm{~mm}$ away from the mid-span in both sides of the bar. Also the strains of the helical reinforcement were measured using electrical - resistance strain gauges $(5 \mathrm{~mm})$ glued at the bottom, top and sides of the helical reinforcement at the mid-span of the beam and $300 \mathrm{~mm}$ away from the mid-span of the beam. The strain on the compression zone of the beam was measured using two electrical - resistance strain gauges (60 $\mathrm{mm}$ length) glued on the top surface at mid-span of the beam. For each beam, two embedment gauges were placed at a depth of $40 \mathrm{~mm}$, one at the beam's mid-span and the other $300 \mathrm{~mm}$ away from the mid-span of the beam.

The beams were tested under four-point loading regime in the strong floor of the civil engineering laboratory at the University of Wollongong. The displacement-controlled load was applied using a $600 \mathrm{kN}$ actuator. The mid span deflection of the beam was measured using linear variable differential transformers (LVDTs). The LVDT was fixed to a $\mathrm{U}$ shaped steel plate attached at the bottom of the beams. This mechanism was used in order to prevent damage of the (LVDTs) when concrete cover starts spalling off.

Five different measurements were taken at each load increment: the strain at the top surface of the concrete, the concrete strain at $40 \mathrm{~mm}$ depth (using the embedment gauges), the strains in the longitudinal reinforcement, the strains in the helical reinforcement and the mid-span deflection. During testing, all data were recorded using Smart System installed on a PC computer.

\section{ANALYSIS OF TEST RESULTS}

A summary of the test results is presented in Tables $\mathbf{1}$ and 2. Observed load versus mid-span deflection and the observed load versus strain for all ten tested beams are presented in this paper and discussed in the following sections. 
Table 1. Summary of Beam Results

\begin{tabular}{|c|c|c|c|c|c|c|c|}
\hline $\begin{array}{l}\text { Beam Speci- } \\
\text { men }\end{array}$ & $\begin{array}{c}\text { Helical Rein- } \\
\text { forcement Ratio }\end{array}$ & $\begin{array}{l}\text { Concrete Com- } \\
\text { pressive Strength, } \\
\text { MPa }\end{array}$ & $\begin{array}{l}\text { Load at Cover } \\
\text { Spalling off, } k N\end{array}$ & $\begin{array}{c}\text { Failure } \\
\text { Load, kN }\end{array}$ & $\begin{array}{c}\text { Yield De- } \\
\text { flection } \\
\Delta_{y}, \mathbf{m m}\end{array}$ & $\begin{array}{c}\text { Ultimate } \\
\text { Deflection } \\
\Delta_{\mathrm{u}}, \mathrm{mm}\end{array}$ & $\begin{array}{c}\text { Displacement } \\
\text { Ductility Index } \\
\Delta_{\mathrm{u}} / \Delta_{\mathrm{y}}\end{array}$ \\
\hline 8HP25 & 0.050 & 80 & 297 & 346 & 32 & 185 & 5.7 \\
\hline 12HP50 & 0.057 & 100 & 386 & 340 & 35 & 193 & 4.6 \\
\hline 12HP75 & 0.038 & 100 & 388 & 310 & 32 & 65 & 2 \\
\hline 8HP75 & 0.017 & 80 & 381 & 300 & 40 & 45 & 1.1 \\
\hline 12HP100 & 0.028 & 100 & 398 & 260 & 33 & 52 & 1.6 \\
\hline 8HP100 & 0.013 & 80 & 326 & 250 & 34 & 41 & 1.2 \\
\hline
\end{tabular}

*the load dropped suddenly.

Table 2. Summary of Beam Measured Strains at $40 \mathrm{~mm}$ Depth

\begin{tabular}{|c|c|c|c|c|}
\hline Beam specimen & $\begin{array}{c}\text { Measured Top Surface Strain } \\
\text { Just Before Spalling off Con- } \\
\text { crete Cover }\end{array}$ & $\begin{array}{l}\text { Measured Strain at } 40 \mathrm{~mm} \\
\text { Depth Just Before Spalling off } \\
\text { Concrete }\end{array}$ & $\begin{array}{l}\text { Measured Strain at } 40 \mathrm{~mm} \\
\text { Depth Just After Spalling off } \\
\text { Concrete }\end{array}$ & $\begin{array}{l}\text { Measured Strain at } \\
40 \mathrm{~mm} \text { Depth at } \\
\text { Failure Load }\end{array}$ \\
\hline 12HP25 & 0.00324 & 0.00154 & 0.00315 & 0.0146 \\
\hline $8 \mathrm{HP} 25$ & 0.0034 & 0.001386 & 0.002716 & 0.012459 \\
\hline 12HP50 & 0.00324 & 0.00144 & 0.00296 & 0.011 \\
\hline $8 \mathrm{HP} 50$ & $*$ & 0.001273 & 0.00163 & 0.009155 \\
\hline 12HP75 & 0.00336 & 0.00139 & 0.00281 & 0.008 \\
\hline 8HP75 & 0.0034 & 0.002077 & 0.0049 & 0.004867 \\
\hline 12HP100 & 0.00336 & 0.00137 & 0.00263 & 0.0058 \\
\hline 8HP100 & 0.003 & 0.00119 & 0.00157 & $*$ \\
\hline 12HP160 & 0.0034 & 0.0014 & 0.0014 & 0.0014 \\
\hline 8HP160 & 0.0035 & 0.001824 & 0.001824 & 0.001824 \\
\hline
\end{tabular}

\subsection{Load Versus Mid- Span Deflection}

The main differences between the two series of test beams are the helix bar diameter and the concrete compressive strength. In each series the helical pitch was varied so as to investigate the behaviour of over-reinforced HSC helically confined beams with different condition by using different helical confinement diameter and different concrete compressive strength. The difference between concrete compressive strength affects the ratio of $\left(\rho / \rho_{\max }\right) . \rho_{\max }$ is the maximum allowable tensile reinforcement ratio and has been defined by AS 3600 [11] as Equation 1 and $\rho$ is the longitudinal reinforcement ratio as shown in Equation 2. For the beams confined with $12 \mathrm{~mm}$ diameter helix and $105 \mathrm{MPa}$ concrete, the value of $\rho / \rho_{\max }$ is 1.55 . For the beams confined with $8 \mathrm{~mm}$ diameter helix and $80 \mathrm{MPa}$ concrete, the magnitude of $\rho / \rho_{\max }$ is 1.93 .

$\rho_{\max }=\frac{0.34 \gamma f_{c}}{f_{s f}}$
$\rho=\frac{A_{x}}{b d}$

where

$\gamma=$ ratio under design bending or combined bending and compression of the depth of assumed rectangular compressive stress block to $K_{u} d$.

$K_{u}=$ ratio of depth to neutral axis to the effective depth.

$d=$ effective depth.

$f_{c}=$ characteristic concrete compressive strength at 28 days, $\mathrm{MPa}$.

$f_{s y}=$ yield strength of reinforcing steel, MPa.

$b=$ beam width

$A_{s}=$ longitudinal reinforcement ratio

Figs. (5a-5e) and (6a-6e) shows the load-midspan deflection of the ten tested beams. These figures show the remark- 


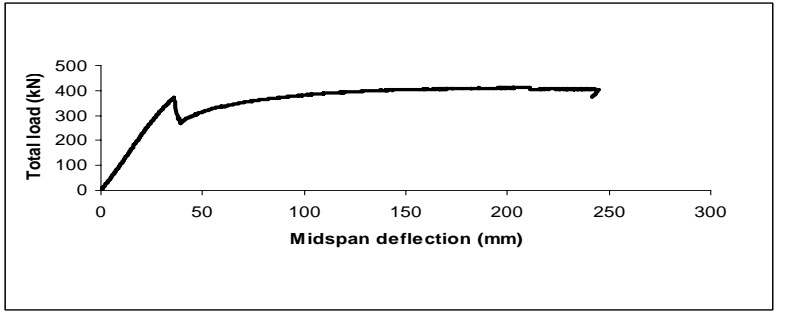

Fig. (5a). Load-deflection curve for beam 12HP25.

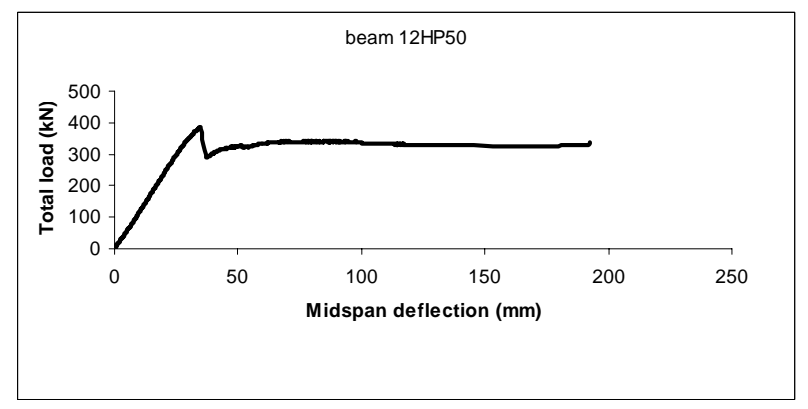

Fig. (5b). Load-deflection curve for beam 12HP50.

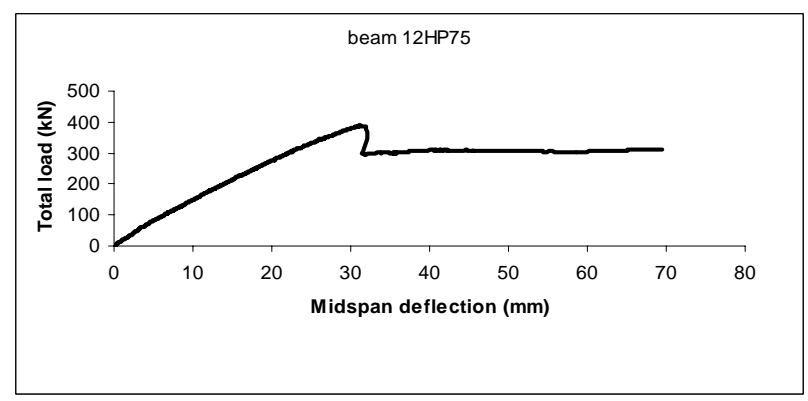

Fig. (5c). Load-deflection curve for beam 12HP75.

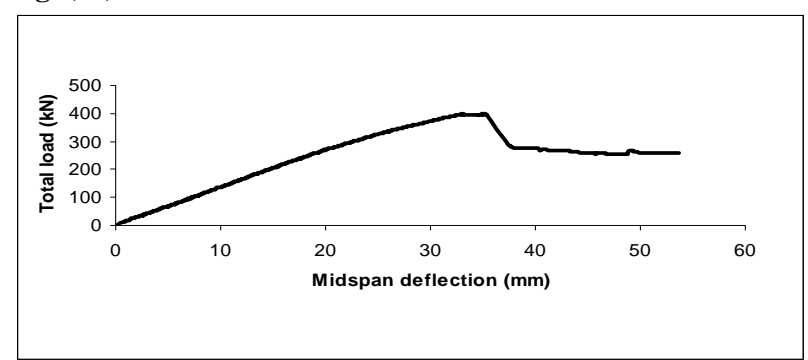

Fig. (5d). Load-deflection curve for beam 12HP100.

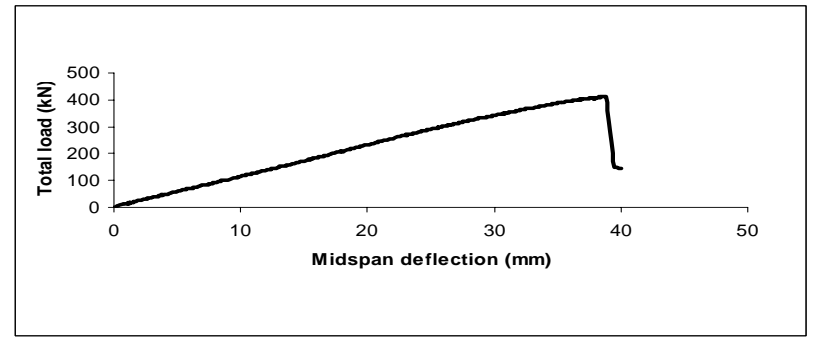

Fig. (5e). Load-deflection curve for beam 12HP160.

able effect of helical pitch on the mid span deflection. Beams which have helical pitches of 25, 50, 75 and $100 \mathrm{~mm}$ failed in a ductile manner. The level of the ductility depends on the helical pitch. Beam 12HP160 failed in a brittle mode, as the upper concrete in the compression zone was crushed and the maximum load was $413 \mathrm{kN}$ and then dropped to $150 \mathrm{kN}$. Also the maximum load for Beam $8 \mathrm{HP} 160$ was $376 \mathrm{kN}$ and then dropped to $94 \mathrm{kN}$. This drop indicates the effect of confinement is negligible when the spacing is equal to the confinement diameter, which is in agreement with the experimental results by Iyengar et al. [16] and Martinez et al. [17]. Fig. (7) shows the relation between the helical pitch and the ultimate mid-span deflection. Beams $12 \mathrm{HP} 25$ and 8HP25 had a maximum deflection of $240 \mathrm{~mm}$ and $185 \mathrm{~mm}$, respectively and the deflection was reduced as the pitch was increased.

Deflection ductility index is defined as the ratio of ultimate deflection to the yield deflection. Fig. (8) shows that the deflection ductility index increases as the helical pitch decreases. It is to be noted that there is no considerable difference between yield deflections for the ten beams compared to the ultimate deflection. Hence, it can be concluded that the deflection ductility index is affected significantly by

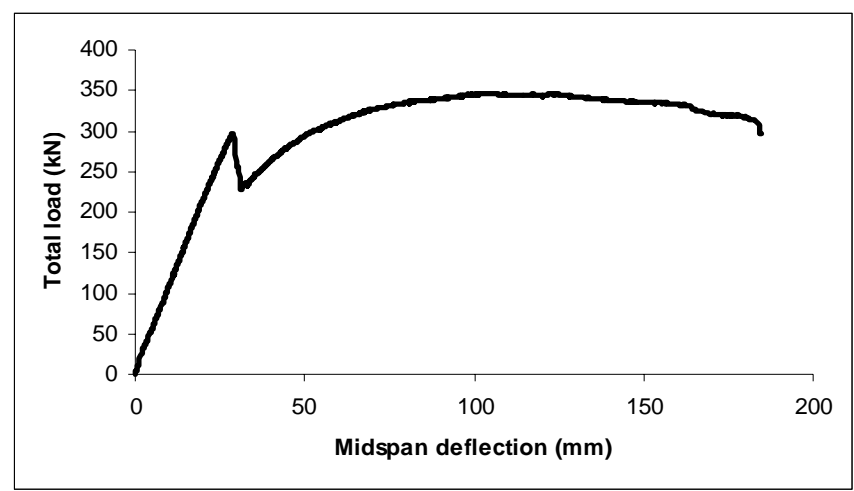

Fig. (6a). Load-deflection curve for beam 8HP25.

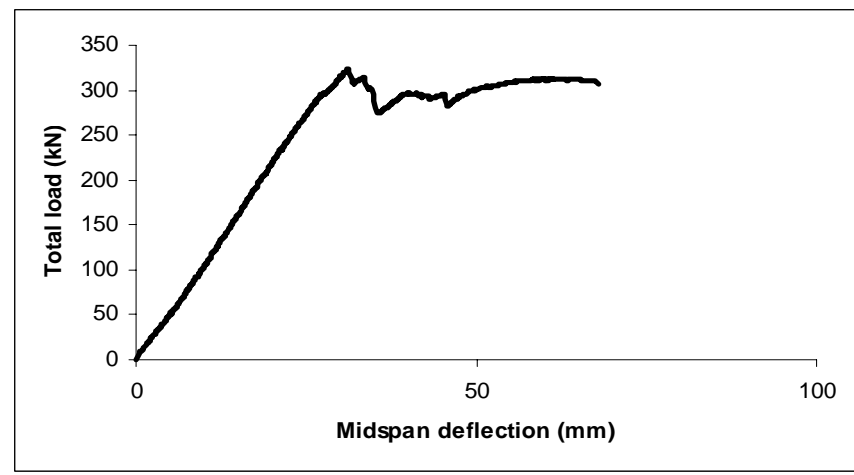

Fig. (6b). Load-deflection curve for beam 8HP50.

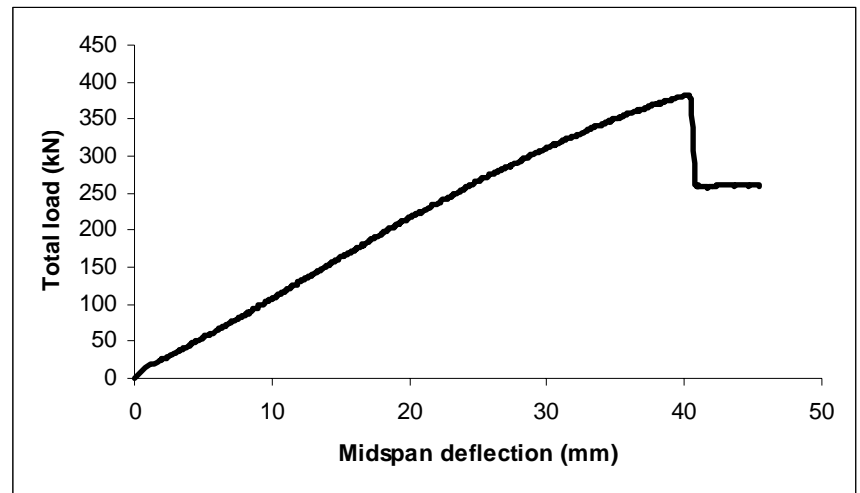

Fig. (6c). Load-deflection curve for beam 8HP75. 


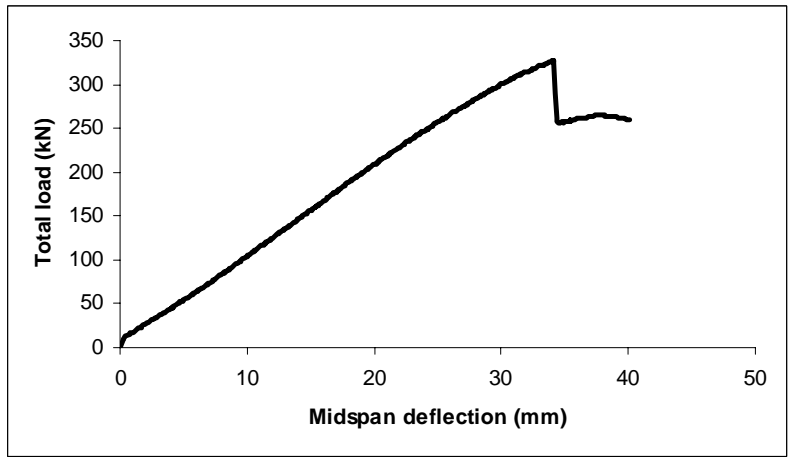

Fig. (6d). Load-deflection curve for beam 8HP100.

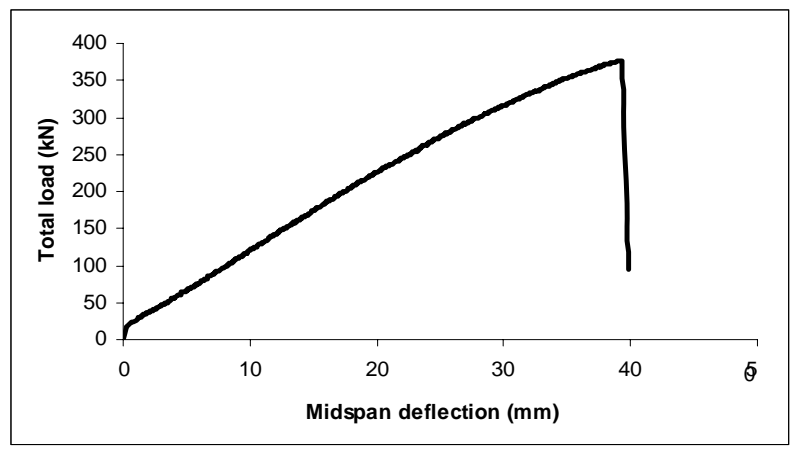

Fig. (6e). Load-deflection curve for beam 8HP160.

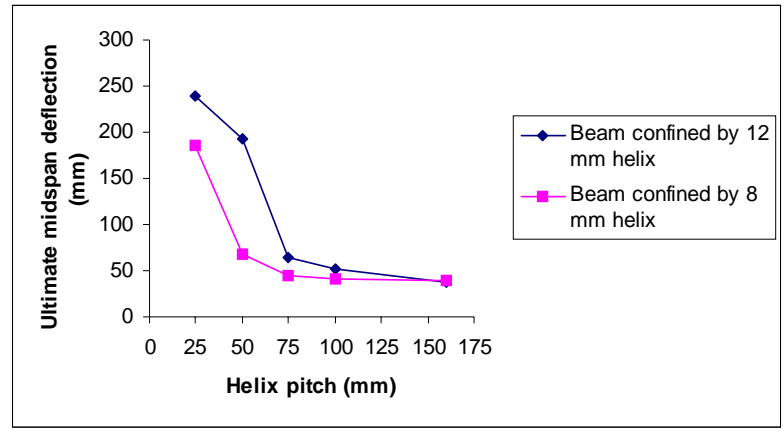

Fig. (7). Ultimate mid-span deflection versus helix pitch.

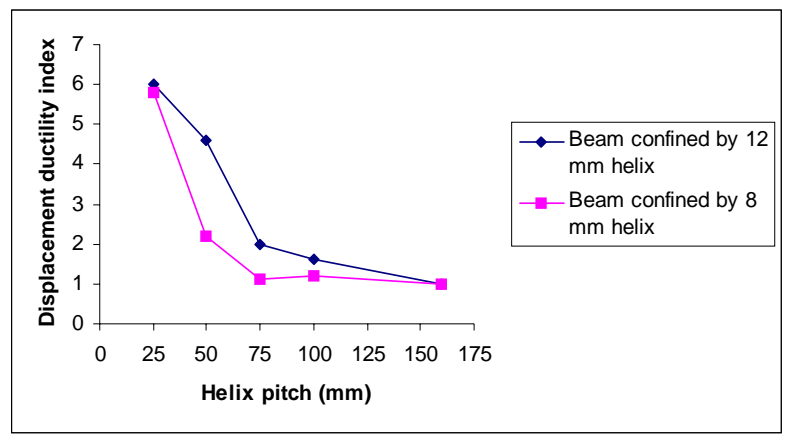

Fig. (8). Effect of helix pitch on normalized displacement ductility.

the ultimate deflection. It could also be concluded that the helical pitch has a significant effect on the ultimate deflection but less significant effect on the yield deflection. Helical pitch is an important parameter in enhancing the ductility of beams.
Fig. (9) shows the relation between the displacement ductility index versus the dimensionless quantity $\frac{\rho_{h} f_{y h}}{f_{c}^{\prime}}$ where $f_{y h}$ is the helical steel strength; $f_{e}^{\prime}$ is the concrete compressive strength and $\rho_{h}$ is the volumetric helical reinforcement ratio expressed in Equation 3.

$\rho_{h}=\frac{\pi d_{h}^{2}}{d_{c} s_{b}}$

Where $d_{h}=$ helix diameter

$d_{c}=$ confined concrete core diameter

$S_{h}=$ helical pitch

In this experimental program the confined concrete core diameter was $160 \mathrm{~mm}$. A best fit linear regression curve was established and is shown in Fig. (9). From that curve it could be concluded that the brittle failure occurs when the $\frac{\rho_{h} f_{y h}}{f_{c}^{\prime}}<0.088$. For beams with $\frac{\rho_{h} f_{y h}}{f_{c}^{\prime}}>0.088$ the displacement ductility increases, therefore, ductility is influenced significantly by the volumetric helical reinforcement ratio. Also it is noted that the negligible gain in displacement ductility is when $\frac{\rho_{h} f_{y h}}{f_{c}^{\prime}}>0.314$. Then the ductile beam has $\frac{\rho_{h} f_{y h}}{f_{c}^{\prime}}$ between 0.088 and 0.314 . In other words, beam failure can change from brittle to ductile failure by providing suitable volumetric helical reinforcement ratio and helix steel strength in the compression zone of the beam with specified concrete compressive strength. In fact the concrete compressive strength is enhanced when the helix resists the concrete core from expansion. In other words, the helix role starts when the confined concrete strength is enhanced (confined concrete strength). The enhancement of confined concrete strength depends on many factors such as helix pitch and helix diameter. Equation 1 shows that by increasing the concrete strength the maximum reinforcement ratio is also increased. As a result, the effective reinforcement ratio becomes below the maximum reinforcement ratio. Generally failure type changes from brittle to ductile by providing the

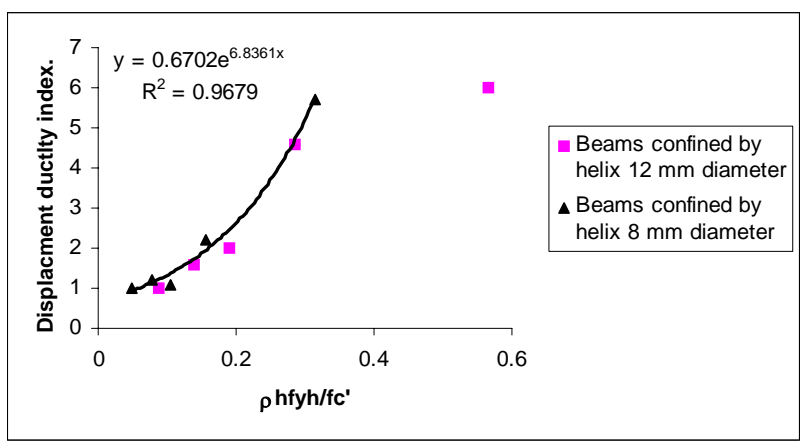

Fig. (9). Influence of helix reinforcement ratio on the displacement ductility index. 
helix in the compression zone of over reinforced HSC beams.

\subsection{Load Versus Strains}

The strain at the top surface of the beam (concrete cover) was recorded to the point where the concrete cover spalled off.

Figs. (10a-10e) and (11a)-11e) show the measured load versus confined strain at $40 \mathrm{~mm}$ depth. Table 2 summarises

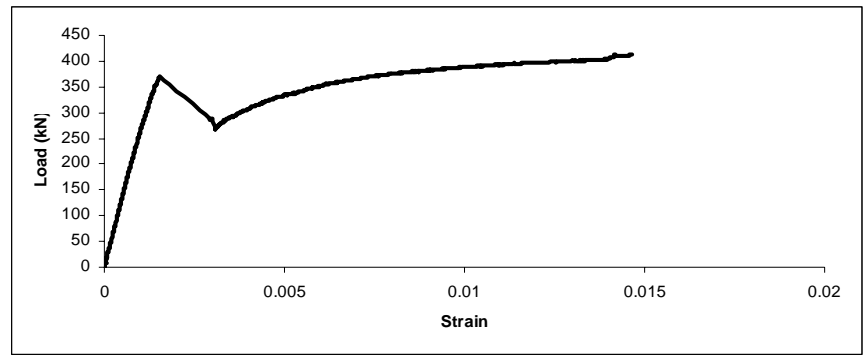

Fig. (10a). Load versus concrete compressive strain at depth 40 $\mathrm{mm}$ from top surface for beam 12HP25.

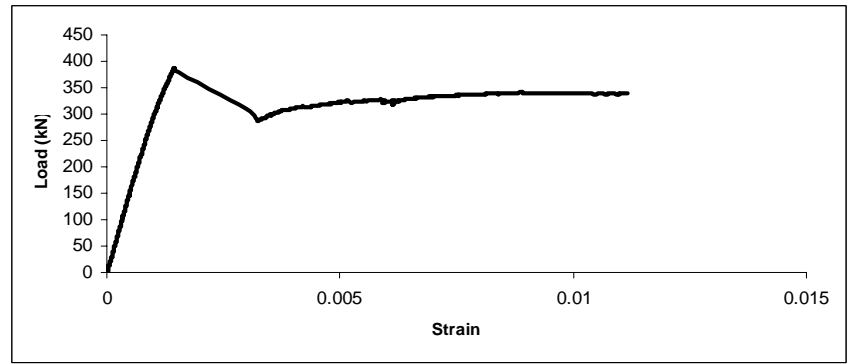

Fig. (10b). Load versus concrete compressive strain at depth 40 $\mathrm{mm}$ from top surface for beam 12HP50.

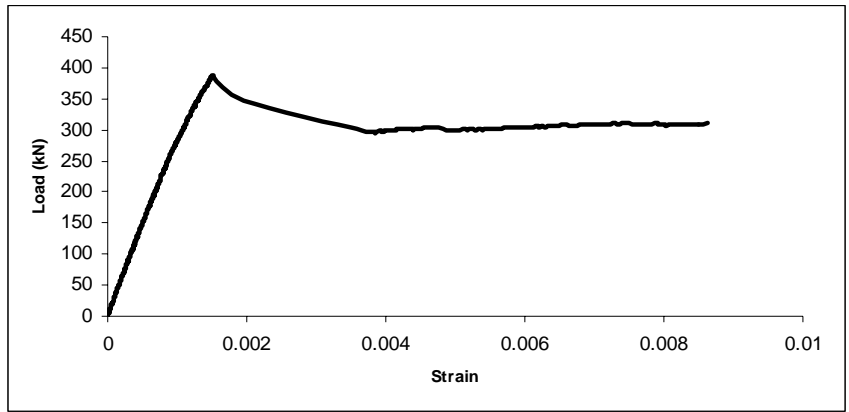

Fig. (10c). Load versus concrete compressive strain at depth $40 \mathrm{~mm}$ from top surface for beam 12HP75.

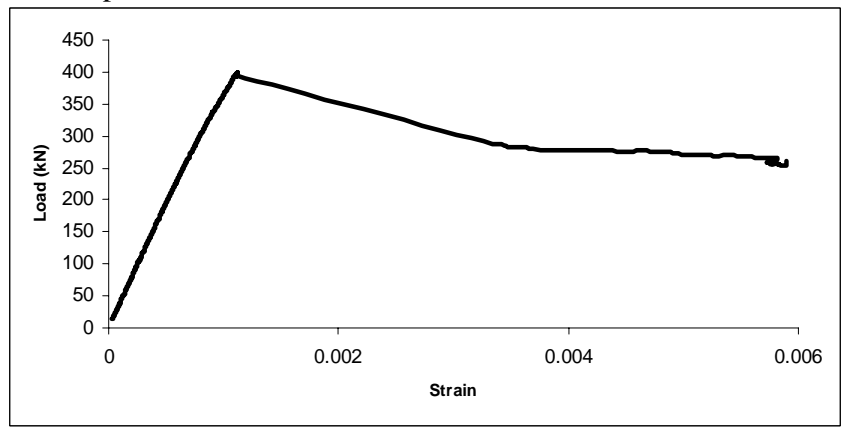

Fig. (10d). Load versus concrete compressive strain at depth 40 $\mathrm{mm}$ from top surface for beam $12 \mathrm{HP} 100$.

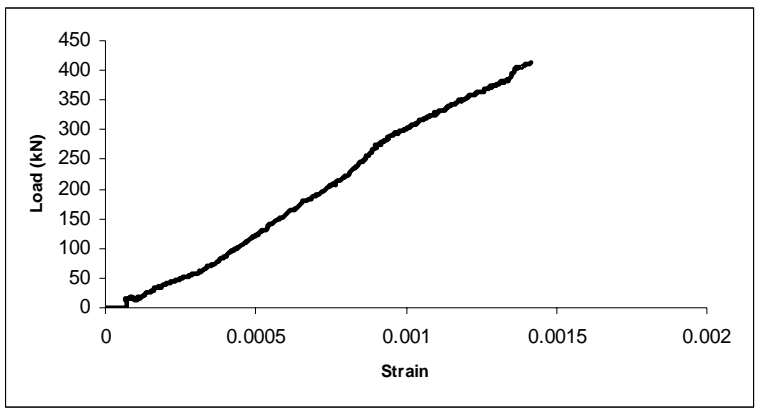

Fig. (10e). Load versus concrete compressive strain at depth $40 \mathrm{~mm}$ from top surface for beam $12 \mathrm{HP} 160$.

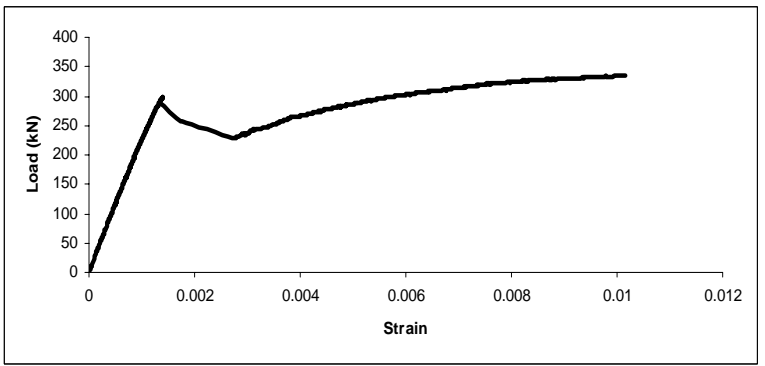

Fig. (11a). Load versus concrete compressive strain at depth 40 $\mathrm{mm}$ from top surface for beam $8 \mathrm{HP} 25$.

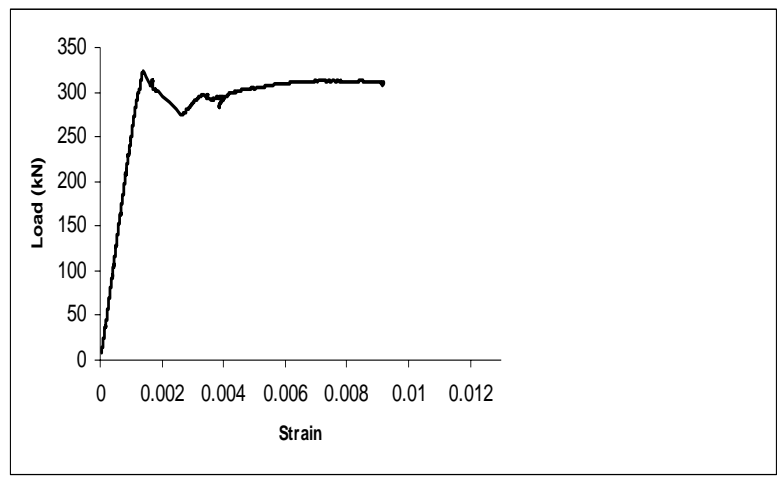

Fig. (11b). Load versus concrete compressive strain at depth 40 $\mathrm{mm}$ from top surface for beam 8HP50.

the measured confined strains at $40 \mathrm{~mm}$ depth and the concrete strains at the top surface of the beams just before concrete cover spalling off. The interesting point is that there was no significant difference between the concrete cover spalling off strain (top surface). However, the average concrete cover spalling off strain for the ten beams was 0.0033 which is in agreement with ACI 318R-02 [12] and AS3600 [11].

Fig. (12) shows the relation between the concrete cover spalling off load and helix pitch and Fig. (13) shows the relation between the failure load divided by the concrete spalling off load of the beams and the helix pitch. The beam 8HP75 is considered as experimental error. The Beam 8HP75 failed in a brittle mode, which was unexpected because for $75 \mathrm{~mm}$ helical pitch, the mode of failure should have been ductile. Also from the beams with $12 \mathrm{~mm}$ helical diameter, it is noted that the spalling off the concrete cover load for the beams, which have helical pitch of $50 \mathrm{~mm}$ and $75 \mathrm{~mm}$ was $386 \mathrm{kN}$ and $388 \mathrm{kN}$, respectively, it is very similar, but the spalling 


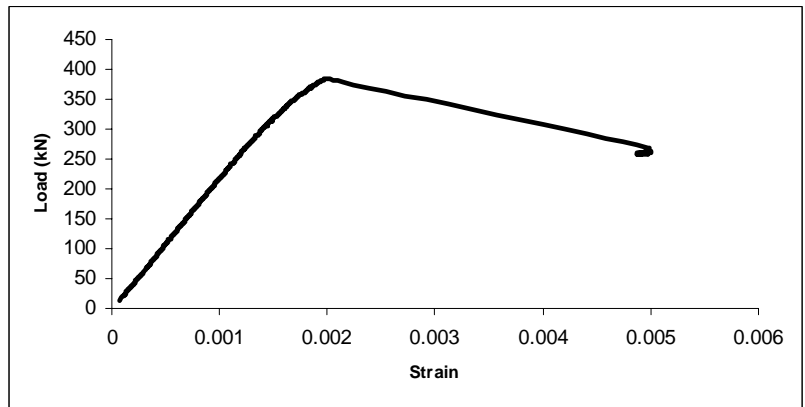

Fig. (11c). Load versus concrete compressive strain at depth $40 \mathrm{~mm}$ from top surface for beam 8 HP75.

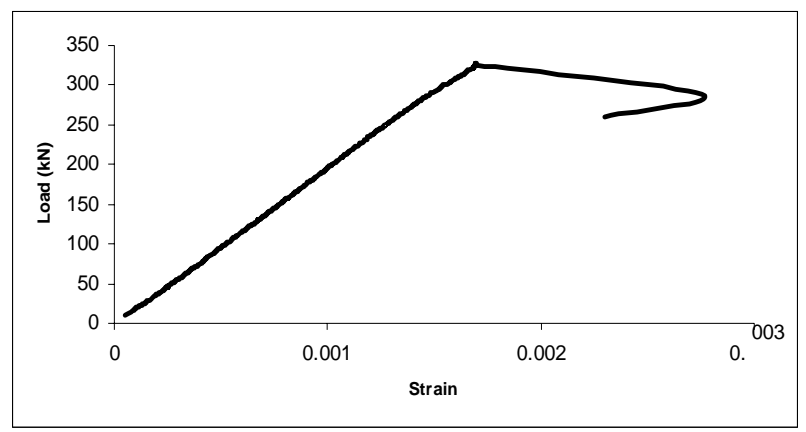

Fig. (11d). Load versus concrete compressive strain at depth 40 $\mathrm{mm}$ from top surface for beam 8HP100.

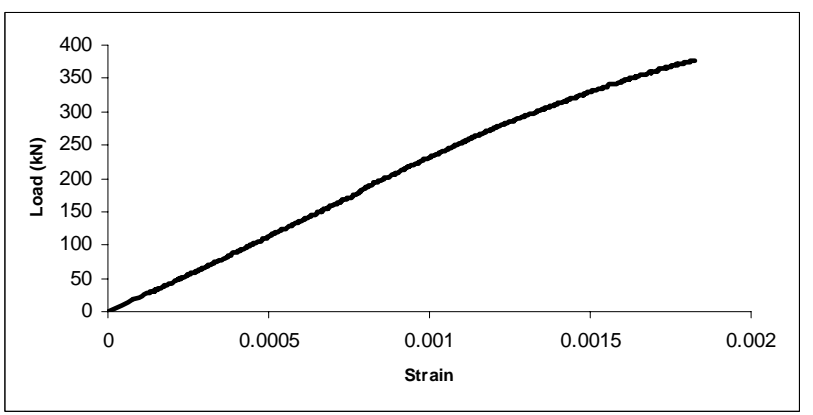

Fig. (11e). Load versus concrete compressive strain at depth $40 \mathrm{~mm}$ from top surface for beam 8HP160.

off concrete cover load of the Beam 8 HP75 was $381 \mathrm{kN}$ which is much more than the spalling off concrete cover load of the Beam 8HP50, which was $324 \mathrm{kN}$. Based on this, it can be considered that Beam 8 HP75 had an experimental error. It is worth noting that the spalling off load increased linearly as the helical spacing increased and the ultimate load decreased as the helical spacing increased. Based on these findings it can be concluded that the spalling off load is directly proportional to the helical pitch and the ultimate load is inversely proportional to the helical pitch.

It is a common belief that closely spaced reinforcement physically separates the concrete cover from the core, causing the early failure of the cover. That statement does not consider the effect of helical diameter or the other variables such as helical yield strength, concrete compressive strength and longitudinal reinforcement ratio, which may have significant effect. It is believed that cover spalling off occurs

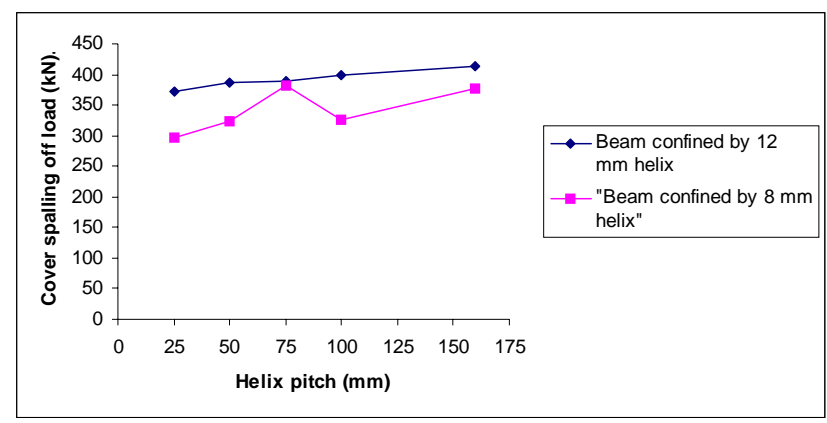

Fig. (12). Cover spalling off load versus helix pitch.

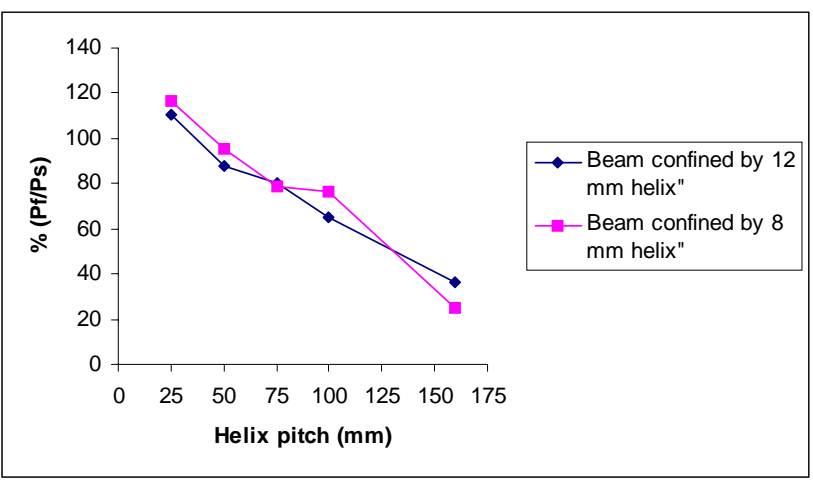

Fig. (13). (Failure load / cover spalling off load) as percentage versus helix pitch.

when the strain in between confined and unconfined concrete changes significantly. In other words, when the strain at the cover becomes less than the strain of the confined concrete, which does not follow the strain gradient as shown in Fig. (14). The experimental results presented in Figs. (10a-e) and (11a-e) and summarised in Table 2 prove that the sudden change in strain (energy release) causes spalling off the concrete cover. For example in beam 12HP25 the strain at 40 $\mathrm{mm}$ depth just before spalling off the concrete cover was 0.00154 and just after spalling off the concrete cover was 0.00315 (the strain at $20 \mathrm{~mm}$ depth is higher than the strains at $40 \mathrm{~mm}$ depth), this remarkable change in strain causes the spalling off the concrete cover. The beam $12 \mathrm{HP} 160$ has no sudden change in strain (strain energy release) because of the negligible effect of the confinement, where the maximum strain at the top surface of the beam was 0.0034 and the failure strain at $40 \mathrm{~mm}$ depth was 0.0014 , which is lower than the strain at the top surface of the beam (no spalling off phenomenon).

The experimental results show considerable displacement ductility index for beams confined with helical pitch 25 and $50 \mathrm{~mm}$. These results promote the use over reinforced beams in a structure safely by adding helical confinement in the compression zone of beams. In different structures such as, high-rise buildings and bridges, beams can be produced economically by increasing the longitudinal reinforcement ratio more than the maximum longitudinal reinforcement ratio allowed by the design codes and then the ductility can be improved effectively by confining the compression zone using helical confinement. In other words when the cross section of the beam is restricted and the beam strength required is more than the nominal strength of the beam if designed as an under reinforced section (the longitudinal rein- 


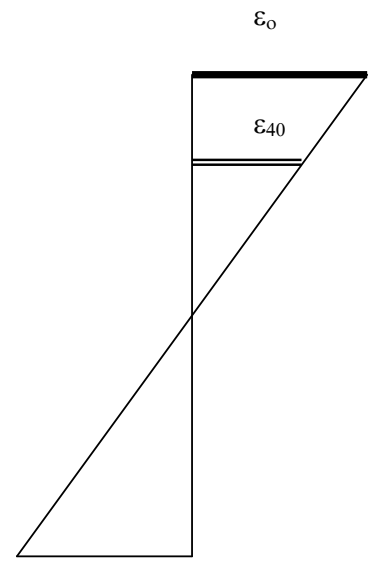

(a)

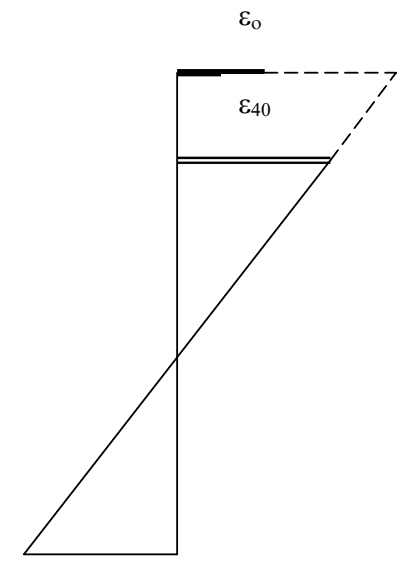

(b)

Fig. (14). (a) Strain distribution before loss of the concrete cover $\left(\varepsilon_{\mathrm{o}}>\varepsilon_{40}\right)$. (b) Strain distribution after spalling off the concrete cover.

forcement ratio is less than the maximum longitudinal reinforcement ratio allowed by the code), then it could enhance the strength up to the required strength by increasing the longitudinal reinforcement ratio and enhancing the ductility by confining the compression zone using the helical confinement with proper pitches.

\section{CONCLUSIONS}

The experimental program in this study is to investigate and provide experimental evidence about the significant effect of helical pitch on the displacement ductility of helically confined HSC beam. Ten over reinforced HSC beams helically confined were tested. Conclusions can be drawn about the behaviour of these beams with different helical pitch of $25,50,75,100$ and $160 \mathrm{~mm}$ and different helix diameter 8 $\mathrm{mm}$ and $12 \mathrm{~mm}$.

The two beams with helical pitch of $160 \mathrm{~mm}$ (equal to the core diameter of the beam) have shown to be very brittle in their failure, providing no plateau region in their load deflection curves. The concrete spalled off at the failure load. The conclusion drawn from testing these beams is that the confinement effect is negligible when the helical pitch is equal to or greater than the core diameter for helically confined beams.

The other beams with helical pitch of 25, 50, 75 and 100 $\mathrm{mm}$ have shown to be ductile and the level of ductility is based on the helical pitch. The helixes effectively confined the compressive region when the helical pitch was reduced. It is interesting to note that the displacement ductility index increases as the helical pitch decreases. In other words, displacement ductility index is inversely proportional with the helical pitch.

There was no significant difference between the yield deflections of the beams but there was significant difference between the ultimate deflections for the ten beams. That is an indicator that the helix effectiveness takes place after yield deflection takes place and then the concrete strength is enhanced (confined concrete strength). The change of con- fined concrete strength depends on many factors such as helix pitch. As a result the failure type changes from brittle to ductile. Generally providing the helix in the compression zone of beams with a suitable helix pitch can enhance the ductility of over reinforced HSC beams reinforced with high strength steel.

The common reason for the spalling off phenomena is that closely pitched helixes physically separate the concrete cover from the core. However, the experimental results show that the spalling off occurred when the strain in between confined and unconfined concrete changed significantly. This change is affected by the helical pitch as well as other parameters such as helical diameter and tensile strength. In other words, there is a considerable release of strain energy responsible for spalling off the concrete cover. The quantity of strain energy release is affected by different factors, one of which is helical pitch. Finally, this study has shown that adopting a suitable helix pitch can enhance the strength and confined compressive strain (ductility) of HSC beams reinforced with high strength steel.

\section{REFERENCES}

[1] S. Hatanaka and Y. Tanigawa, "Lateral Pressure Requirements for Compressive Concrete", in Proceedings of $10^{\text {th }}$ World Conference on Earthquake Engineering, Madrid, 1992, pp. 2603-2608.

[2] W. W. L. Chan, "The Ultimate Strength and Deformation of Plastic Hinges in Reinforced Concrete Frameworks", Magazine of Concrete Research, vol. 7, no. 21, pp. 121-132, 1955.

[3] R. Park and T. Paulay, Reinforced concrete structures, John Wiley and Sons, 1975.

[4] P. A. Whitehead and T. J. Ibell, "Deformability and Ductility in Over-Reinforced Concrete Structures", Magazine of Concrete Research, vol. 56, no. 3, pp. 167-177, 2004.

[5] A. Kwan, J. Ho and H. Pam, "Effect of Concrete Grade and Steel Yield Strength on Flexural Ductility of Reinforced Concrete Beams", Australian Journal of Structural Engineering, vol.5, no. 2, pp.119-138, 2004.

[6] S. P. Shah and B.V. Rangan, "Effects of Reinforcements on Ductility of Concrete", Journal of the Structural Division, vol. 96, no. ST6, pp. 1167-1184, 1970.

[7] M. A. Mansur, M. S. Chin and T. H. Wee, "Flexural Behavior of High-Strength Concrete Beams”, ACI Structural Journal, vol. 97, no. 6, pp. 663-674, 1997. 
[8] M. M. Ziara, D. Haldane and S. Hood, "Proposed Changes to Flexural Design in BS 8110 to allow Over-Reinforced Sections to Fail in a Ductile Manner", Magazine of Concrete Research, vol. 52, no. 6, pp. 443-454, 2000.

[9] S. A. Sheikh and S. M. Uzumeri, "Strength and Ductility of Tied Concrete Columns", Journal of the Structural Division, vol. 106, no. 5, pp. 1079-1102, 1980.

[10] D. Cusson and P. Paultre, "High-Strength Concrete Columns Confined by Rectangular Ties", ACI Structural Journal, vol. 120, no. 3, pp. 783-804, 1994.

[11] AS3600, Australian Standard for Concrete Structures, Standards Association of Australia, North Sydney, 2001.

[12] ACI 318-02, Building code Requirements for structural concrete, American Concrete Institute. Michigan, 2002.
[13] M. N. S. Hadi and L. C. Schmidt, "Use of Helixes in Reinforced Concrete Beams", ACI Structural Journal, vol. 99, no. 2, pp. 304314, 2002.

[14] N. M. Elbasha and M. N. S. Hadi, "Experimental Testing of Helically Confined HSC Beams", Structural Concrete, Thomas Telford and Fib, vol. 6, no. 2, pp. 43-48, 2005.

[15] S. W. Shin, S. K. Ghosh and J. Moreno, "Flexural Ductility of Ultra-High Strength Concrete Members", ACI Structural Journal, vol. 86, no. 4, pp. 394-400, 1989.

[16] K. T. Iyengar, R. Sundra, P. Desayi and K. N. Reddy, "StressStrain Characteristics of Concrete Confined in Steel Binders", Magazine of Concrete Research, vol. 22, no. 72, pp. 173-184, 1970.

[17] S. Martinez, A. H. Nilson and F. O. Slate, "Spirally Reinforced High-Strength Concrete Columns", ACI Structural Journal, vol. 81, no. 5, pp. 431-442, 1984.

Received: March 31, 2008

Revised: September 17, 2008

Accepted: September 18, 2008

(CHadi and Elbasha.; Licensee Bentham Open.

This is an open access article licensed under the terms of the Creative Commons Attribution Non-Commercial License (http://creativecommons.org/licenses/by-nc/3.0/) which permits unrestricted, non-commercial use, distribution and reproduction in any medium, provided the work is properly cited. 